TI 2001- 025/3

Tinbergen Institute Discussion Paper

An Environmental- Economic

Assessment of Genetic

Modification of Agricultural

Crops

Jeroen C.J.M. van den Bergh

Justin M. Holley 


\section{Tinbergen Institute}

The Tinbergen Institute is the institute for economic research of the Erasmus Universiteit Rotterdam, Universiteit van Amsterdam and Vrije Universiteit Amsterdam.

\section{Tinbergen Institute Amsterdam}

Keizersgracht 482

1017 EG Amsterdam

The Netherlands

Tel.: $\quad+31 .(0) 20.5513500$

Fax: $\quad+31 .(0) 20.5513555$

\section{Tinbergen Institute Rotterdam}

Burg. Oudlaan 50

3062 PA Rotterdam

The Netherlands

Tel.: $\quad+31 .(0) 10.4088900$

Fax: $\quad+31 .(0) 10.4089031$

Most recent TI discussion papers can be downloaded at http:// www.tinbergen.nl 


\title{
An Environmental-Economic Assessment of Genetic Modification of Agricultural Crops
}

\author{
Jeroen C.J.M van den Bergh \\ and \\ Justin M. Holley \\ Department of Spatial Economics \\ Faculty of Economics and Econometrics \\ Free University \\ De Boelelaan 1105 \\ 1081 HV Amsterdam \\ The Netherlands \\ jbergh@econ.vu.nl
}




\begin{abstract}
The advantages and disadvantages of genetic modification of organisms (GMOs) for agriculture are reviewed. These relate to the environment, human health, economic benefits, population growth, and consequences for developed and developing countries. An overall evaluation requires that attention is given to uncertainty, risk perception and endogeneity, irreversibility, and the trade-off between costs and benefits. The uncertainty surrounding both pros and cons explains the wide range of opinions about the use of GMOs in agriculture. Given that modern biotechnology is subject to much R\&D and genetically modified products are already being sold at a large scale, it seems unrealistic, and certainly too late, to strive for a complete ban of GMOs. Instead, an effective public strategy should include a number of elements: promote communication among science, industry, politicians, voters/consumers, and NGOs; focus legislation on responsibilities of private firms; correct prices to reflect environmental and health impacts of GMOs (externalities); develop standards for monitoring and testing environmental, ecological and health consequences of GMO based products; and guarantee consumer choice between products based on and products free of production cycles that involve genetic engineering or GMOs.
\end{abstract}

Keywords: Biotechnology, Cost-benefit analysis, Ecology, Evolution, Genetic engineering, Health, Irreversibility, Transgenic plants, Uncertainty. 


\section{Introduction}

Modern biotechnology, also known as genetic engineering or modification of organisms, has recently enjoyed a great deal of public attention, in the media, on internet, and in the political arena. Proponents of rapid implementation of this technology, notably in agriculture and medicine, point at its beneficial effects on both quality and quantity of food produced by agriculture and food processing industries. Biotechnology is argued to lead to more nutritious, durable, tasty and cheaper food. Although the debate concerning biotechnology in agriculture is taking place mainly in the western world, the major potential winners are suggested to be the developing countries. Opponents of biotechnology use terms such as "Frankenstein food" and "genetic manipulation" to point at its unnaturalness, and the associated dangers, such as negative impacts on human health and the natural environment. So far, these counter arguments have come mainly (but not exclusively, see Union of Concerned Scientists) from environmental organizations, notably Greenpeace (see Greenpeace online). Their writings, however, are dominated by emotional considerations and often lack a firm scientific basis. On the other hand, many scientists, both biologists and physicians, are openly in favor of genetic engineering and actively promote its use. Interestingly, various academic bioengineers working at universities are themselves involved in commercially applying their scientific findings, making them perhaps not the most objective judges of any risks involved. In this article the various opinions will be substantiated with references to relevant publications.

Without any doubt, like any technology, biotechnology has both positive and negative consequences. This article aims to examine and compare the pros and cons of biotechnology applied to food production. The main focus of attention here will thus be the use of genetically modified organisms (GMOs), in particular transgenic plants, in the agricultural sector. The discussion comprises biological, environmental, health and economic issues. Particular attention will be devoted to the way uncertainty can be addressed in evaluating potential social costs and benefits of biotechnology applications.

The basic motivation for writing this article is the belief that consumers, producers, politicians, and activist groups should be properly informed about the risks and benefits of biotechnology in order to be able to make deliberate choices about related investment, buying, and voting decisions. Nevertheless, it is not clear whether this is a realistic goal, given the rather technical nature of the issues involved. These cover an extremely wide range of human knowledge: genetics and biochemistry, evolutionary biology, ecology, health sciences, ethics, legislation and liability, patenting, new markets, takeovers and mergers, trade and globalization, and even psychology (to analyze emotional responses). Unfortunately, ill-informed articles are being published on a daily basis in newspapers and popular magazines. As social scientists involved in environmental research we also run the risk of making these types of mistakes, particularly in the area of natural sciences. Nevertheless, a natural scientist would face the same problem with the social aspects. A truly multidisciplinary evaluation is therefore required. Consequently, someone seriously interested in forming an opinion about the role of biotechnology in our society should be willing to invest considerable time and effort in studying relevant natural and social science aspects of the issues involved. This article offers a first effort in this direction. 
The organization is as follows. Section 2 presents a definition and a short history of biotechnology, as well as some indicators of its economic significance. Section 3 offers arguments in favor of using GMOs in agriculture, classified into environmental, human-economic, and population-development related benefits. Section 4 lists the arguments against it, covering environmental, health, social-economic, and populationdevelopment related costs. Section 5 discusses how the pros and cons of biotechnology can be evaluated, paying attention to the analysis of risk and uncertainty, the trading-off of benefits and costs, and the comparison of alternative options in agriculture. Section 6 concludes.

\section{Biotechnology}

Definition

Although they are often used synonymously, there is a strict difference between biotechnology and genetic engineering. The definition of biotechnology given in 1992 during the Convention on Biodiversity states that it includes "any technological application that uses biological systems, living organisms or derivatives thereof, to make or modify products or processes for specific uses" (Committee on Agriculture, 1999, p.2). Biotechnology covers all techniques that involve the isolation, amplification, modification, and recombination of DNA. Genetic engineering is only one of these techniques, but it is by far the most debated. It can be seen as a particular type of biotechnology that involves the modification of DNA and the transfer of gene components between species in order to encourage replication of certain specific traits (Altieri, 1998). Most of the debate on biotechnology, especially in agriculture, focuses on the use of genetic engineering to produce genetically modified organisms or transgenic products. These various terms will be used throughout the paper.

\section{History}

Biotechnology has been around for centuries. Products such as yogurt, cheese and beer have always been made in a process that is presently best referred to as traditional biotechnology (McHugen, 2000). To the same category belongs crossbreeding, which aims at combining positive traits of different varieties of the same species in order to create organisms with certain attractive properties. Since the process of crossbreeding combines whole strings of DNA it is limited to mixing varieties of the same species. A particular application of crossbreeding is in animal husbandry, where certain varieties of a species have been crossed so as to create a wide range of domesticated animals. Nowadays, virtually every type of foodstuff, with the exception of wild game and wild fruit, has been modified in some way, so as to make it more attractive or resourceful, or its production more efficient. This has been done using either traditional or modern biotechnology.

Modern biotechnology is a relatively young technology. It can be classified into the genetic modification of plants, animals or micro organisms that are used either for agricultural, medicinal or industrial purposes. Recombinant-DNA techniques, which are at its basis, were first applied in the 1970's. They allowed the cutting and slicing of genes of one organism and the insertion of them into another organism, thus changing the latter's production of certain proteins so as to indirectly remove from it undesirable or 
add to it desirable features. ${ }^{1}$ The first genetically modified plants were produced in 1983 and the first modified whole food entered the market in 1994 (McHugen, 2000). The fundamental difference between traditional biotechnology and genetic engineering is that the latter allows the crossing of species' boundaries. Genetic engineering even allows the transfer of genes from animals to plants and vice versa.

\section{Biotech companies}

Although the modern biotech industry is young, it has experienced a tremendous growth over the past three decades. Sales have been estimated to grow $16 \%$ over 1999 leading to an estimated US $\$ 18.6$ billion in revenues (Morrison, Giovannetti et al., 1998). The growth of sales of transgenic crops has been even more dramatic. In 1995 global sales were estimated at US\$75 million, while for 1999 estimates range between US\$2.1 and US $\$ 2.3$ billion. Furthermore, total sales for the year 2010 are estimated to reach US\$25 billion (James, 1999).

Research and development $(\mathrm{R} \& \mathrm{D})$ plays a very important role in the biotechnology industry. In 1999, the US biotech industry spent an estimated US\$9,9 billion on R\&D (Morrison, Giovannetti et al., 1998). To see the relevance of GMOs for production of staples in agriculture, note that in 1999 genetically modified soya in USA used on average $50 \%$ of total land use by soya. For maize the equivalent figure is $34 \%$ (James, 1999).

There are also several public sector organizations involved in the biotechnological research and production process. Most public research focuses on seeking benefits involving small scale farmers and improving production in tropical and subtropical environments (The Third World Academy of Sciences, 2000). However, current funding for international agricultural research centers is less than US\$350 million while the support provided by the US government for agricultural research has dropped by about $30 \%$ in real terms since 1960 (Shah and Strong, 1999). The result is that unlike during the green revolution where public organizations played a mayor strategic roles, the main players in biotechnology development are private, profit seeking firms.

Responses by consumers, NGOs and even countries already have had quite a lot of influence on the operations and marketing of the private biotech companies. Several large food companies have recently changed their strategies based on fear for their reputation and market share. This does not mean, however, that the production of genetically modified products is decreasing. The main change is that certain products that contain artificially modified proteins are not being sold to consumers at this moment. But a range of other products like butter, cookies, soups, bread and sauces with ingredients from GMOs are still available. Environmental NGOs claim that firms in the foodstuff industry pay little attention to the production methods of the ingredients of their products (Reijnders, 2000). In this sense biotechnology is no exception; standards for labor, environmental and biotechnological characteristics of products and production processes have been discussed at an international level for a long time now, notably in a GATT/WTO context. It is just a matter of time before such standards will be

\footnotetext{
${ }^{1}$ The blueprint for each organism is the set of chromosomes or DNA molecules in each of its cells. These molecules consist of building blocks called genes. Certain groups of genes provide the code for the production of particular proteins.
} 
internationally agreed upon, including those relating to applications of modern biotechnology.

\section{Arguments in favor of biotechnology}

While the application of modern biotechnology is relatively new, the benefits to farmers, consumers and the environment should be viewed in a long term perspective. The arguments presented in favor of biotechnology can be divided into three categories, namely environmental benefits, human-economic benefits, and benefits associated with population growth in developing countries.

\section{Environmental benefits}

Although agriculture offers many opportunities for biotechnological applications, most efforts have been focused on using genetic engineering to either develop herbicide tolerant crops or pest and disease resistant crops (Altieri, 1998). Herbicide Resistant Crops (HRCs) contain a new gene that protects the crop against harmful effects of certain weed killers. Farmers can then spray these crops with the relevant herbicides to kill off all the weeds while leaving the crops unharmed. The use of these crops could lead to a reduction in the use of herbicide due to the following reasons. First, the application rates for some of the herbicides used on HRCs are less than the application rates of the herbicides being replaced. Second, multiple herbicide treatments on normal crops could be replaced by one herbicide treatment on HRCs, reducing the overall quantity of herbicide. Lastly, herbicides are often used as pre-emerging options, meaning agricultural land is treated for weeds before the weeds emerge as this is easier than if the weeds had to be dealt with once the crop is up. As the quantity of weeds is unknown, the farmer is unsure about what the damage the weeds will cause. As a form of personal insurance and a prevention of loosing a large portion of his crop, the farmer may spray more than necessary. In contrast, using HRCs will lead to a greater use of post emergence treatment, meaning spraying after the crop is up. The farmer can then weigh the costs of another herbicide treatment against the possible damages incurred by the weeds. The resulting increase in effectiveness of herbicide spraying due to the use of biotechnology could reduce the overall use of herbicides, although certainly not make it superfluous. (Krimsky and Wrubel, 1996).

The validity of these arguments depends on the behavioral responses of farmers. It could be expected that because of the increased simplicity and efficiency of the herbicide, farmers would use it on more crops over longer periods of the growing season. The overall result would be an increase in the total amount of herbicide use. Two factors, however, make it less likely that an increase in herbicides will occur. First, herbicides are already used intensively. Over $90 \%$ of all cotton, corn and soybean acreage in the US is treated with herbicides at least once a year (Krimsky and Wrubel, 1996). Second, the first experiences with genetically modified cotton show an increase in yield and net return while using a stable quantity of herbicides. At the same time, for soya a small increase in yield and a significant reduction in herbicide use were found (Klotz-Ingram et al., 1999).

Recently, much attention has been given to crops that can produce an insectkilling toxin called $B t$, named after the soil microorganism Bacillus thuringiensis that has been used for several decades as an insect repellent. Scientists have been able to isolate the genes of the microorganism that produces the toxin and insert these into various types 
of plants. This allows the resulting genetically modified plants to produce their own toxin. Those in favor of this type of biotechnology note that as the crops themselves now produce an insect killing toxin, there is no more need to spray so that the expected overall effect is a reduction in insecticide use.

One particular transgenic crop producing $B t$, namely modified corn, has given rise to much negative public response. Studies have assessed negative effects of genetically modified corn pollen on monarch butterfly caterpillars, in particular since it killed monarch butterfly larvae (Losey et al., 1999). Opponents mention this as a prime example of the ecological risks associated with genetically modified crops. One should be careful, however, in drawing quick conclusions, since new research has stated that the overall effect in this particular case was not worrisome, and not greater than ex ante expected (MacKenzie, 1999).

In the past five decades, more than a quarter of the world's cropland, pastures and woodlands has degraded through misuse or overuse. Additionally, approximately $70 \%$ (and up to $90 \%$ in China and India) of the world's fresh water supply is being used for agricultural purposes, while it is expected that by the year 2025, one quarter of the world population will lack an adequate supply of fresh water (Shah and Strong, 1999). A potential environmental benefit of transgenic crops is that in the future they may allow the use of marginal lands for farming purposes. This requires the creation of crops that can grow on salty, dry or acidic soils. As an indirect effect deforestation for creating cropland could be reduced. Nevertheless, progress in developing such improved crops is rather slow, due to the fact that many more genes are involved, making the engineering task much more complicated than in the case of, for example, the creation of herbicide tolerant or pest resistant crops.

\section{Human and economic benefits}

The main human and economic benefits of agricultural biotechnology are an increase in food quantity and quality, reduced costs of production, and ultimately lower prices of agricultural products.

Improving food quality involves features like an improvement of texture, taste, appearance, and nutritional value. In addition, the ripening of fruits and vegetables can be delayed. Examples of this are increasing the dry matter content of a tomato (Le Buanec, 1999; McHugen, 2000), increasing the concentration of unsaturated fatty acids in soya beans, and altering seed storage proteins (Mazur et al.,1999; McHugen, 2000). Specific improvements for producers are an increased flexibility during production, harvesting, storage, distribution, and transport stages, leading to a reduction of overall production costs. The main changes for consumers are enhanced durability, higher quality, and lower prices of products.

An important feature of agricultural biotechnology is its potential to increase the nutritional value of food. Approximately 125 million children have a diet that lacks a sufficient quantity of vitamin $A$, leaving some 14 million children with irreparable eye damage (Shah and Strong, 1999). Furthermore, is estimated that $30 \%$ of the world population suffers from a lack of iron in their diet, leading to learning disabilities, an increase of infections, and a reduction in the capacity to deliver work. Biotechnology scientists have now created a rice variety that produces significant amounts of vitamin $A$. 
Other varieties are developed that will contain about twice the amount of iron in the current rice (McGloughlin, 1999).

In addition, biotechnology can increase crop yields, which is particularly useful for important staple food such as potatoes, rice, maize, wheat, cassava, and beans (McHugen, 2000). This can be done in various ways. In the first place, the transgenic characteristics discussed above indirectly contribute to a higher productivity of agriculture. In addition, specific techniques are available for increasing yield of single plants. An example is the so-called dwarfing technique, which focuses production of plants in the reproductive parts (Peng et al., 1999). This is useful when these are the source of food products, which is the case for a large number of fruits.

Another future innovation expected from biotechnology is edible vaccines. These could have a much greater impact at a fraction of the cost than the current actions by international institutions like the World Health Organization (McGloughlin, 1999; McHugen, 2000).

\section{Benefits related to population growth and developing countries}

An important argument in favor of biotechnology is the idea that it is essential for guaranteeing sufficient food to feed future world populations. It is estimated that currently approximately 840 million people suffer from hunger every day. Furthermore, while the world population is expected to increase by more than 2 billion until 2020, productivity gains in agriculture have dropped to about $1.3 \%$ per year, half of what they were 30 years ago (Shah and Strong, 1999). In the absence of productivity gains or a world wide expansion of cropland, a global shortage of food at some future date is conceivable.

Over $80 \%$ of the population will be living in developing countries. It is likely that by the year 2020, developing countries will have turned from being net exporters of agricultural products to net importers. Unsustainable agriculture is a significant problem for many of these developing countries, and biotechnology could play an important role in alleviating it (Committee on Agriculture, 1999; Conway, 2000). Low cost, high resistance, and high yielding crops are possible solutions that may prove to be valuable in preventing future famines. Biotechnology can contribute to a production of larger quantities of food and an increase of the nutritional value of different types of food. Some think that biotechnology will perhaps not relieve all poverty or social imbalances in developing countries, but it does have the potential to improve the position of many chronically underfed people, i.e. the extremely poor in this world. Nevertheless, it should be noted that the majority of the research on transgenetic plants is of private origin and focuses on the production of crops grown in developed countries. Therefore, unless government spending increases or private investment is stimulated in another direction, the benefits for developing countries and their populations will remain rather small.

\section{Arguments against the use of biotechnology}

The arguments against modern biotechnology in agriculture can be divided into four categories: ecological and environmental impacts, human health impacts, population growth, and general social-economic consequences.

In addition, there are ethical and religious arguments against the use of biotechnology. These are beyond the scope of this article (see, e.g., Nuffield council on Bioethics, 1999). 


\section{Ecological and environmental issues}

There are at least four main environmental and ecological aspects that should be mentioned. First, crops may transfer genes to wild varieties. Second, genes may be transferred into the soil. Third, insects can become resistant to the pesticides produced. Finally, non-target species in a wider ecosystem context may be affected in some way.

Each crop is member of a plant family to which many different varieties of the same species belong. By introducing new genes into an existing crop, scientists are creating a new variety of the plant, which in turn may effect the surrounding environment, including other varieties of the same species. The danger is that genes of the genetically modified crop transfer to other wild or domesticated varieties of the same crop.

One of the most important risks of using genetically modified crops is that they may influence the original natural or wild species that is the source of the domesticated, agricultural crop. For instance, if genes, such as herbicide tolerant genes, are inserted into a crop with the purpose of fortifying it, then a flow of these genes to the wild variety can improve the fitness of the latter. It may become resistant to herbicides and thus dominate under natural conditions, possibly reducing the genetic variety of the original wild species (Altieri, 1998). This problem is similar to that of newly introduced exotic species. These often meet little control from natural enemies or competitors in ecosystems where they enter, so that they can grow quickly in population size and damage the original species as well as the ecosystem. In a similar way a gene flow from transgenic species to wild relatives creates a risk to local and ultimately global biodiversity.

Another serious problem is related to the fact that wild relatives of crop plants provide a source of genetic diversity that is essential for maintaining the quality and desirable characteristics of the domesticated species. Therefore, to preserve agriculturally relevant biodiversity wild relatives of crop species need to be protected from direct influences, in particular genetically modified relatives. These should be kept as much as possible spatially separated. Nevertheless, in 1996 the EU allowed a GMO, namely a type of coleseed to be grown in Europe, which is its area of origin. This implies a direct risk for the wild relative and thus for the biodiversity that is of value to future agriculture.

Research that has tried to assess the probability of gene transfers from genetically modified crops to other varieties tempers the above concerns somewhat. The results show that the probability of gene transfers from crops created through genetic modification is small, and in fact similar to that for crops created through the use of crossbreeding. An explanation for this is that wild species have been adapting to their surroundings for a very long time, being subject to continuous selection pressure. Newly created, genetically modified varieties that have not passed such a selection and adaptation process are expected to perform less well under natural conditions (The Royal Society, 1998). On the other hand, these considerations do not provide any safeguard. Moreover, it should be noted that as genetically modified crops have been grown on a large scale for only a short period of time, more research is needed to provide for more robust empirical results.

Next, GMOs may affect species that are genetically unrelated but ecologically related, such as their predators, preys, and competitors. Several types of influences can be identified. To begin with, the effect that the newly inserted genes may have on (soil) bacteria is thus far unknown. Even though it is thought to be highly unlikely that the 
effect will be great, it is known that bacteria can absorb DNA from the environment. The consequences of this remain to be seen.

Furthermore, biotechnology can speed up the creation of resistance in weeds and insects against herbicides and insect killers that are being used. As large quantities of genetically modified corn, cotton, soya and rice is produced which generate $B t$, or which are resistant to certain herbicides, the chance of adaptation by weeds and insects to the combination of GMOs and use of herbicides and insecticides is high (Stix, 1998).

External use of $B t$ has been common practice since the 1940's. It is considered the most effective microbial insecticide. Nevertheless, its sales represent little over $1 \%$ of total insecticide sales, as treatment of crops is mainly based on synthetic insecticides (Krimsky and Wrubel, 1996). So far it has turned out to be an effective insect control for home gardening purposes, but the possibility of a reduction in its effectiveness due to GMOs producing $B t$ is very real.

Finally, the effect of transgenic crops on the wider ecosystem can occur, among others, via negative or positive impacts on non target species, usually insects, or via changes in farm management that influence local biodiversity (Hails, 2000). An example of a positive impact on a species is an ecological advantage due to genes contributing to pest resistance. This can in turn have a disturbing impact on the foodweb in the ecosystem. Such effects are not unlikely since farmland is usually close to natural areas providing a habitat for wild species.

Another relevant issue here is that perfection of crops through genetic modification promotes monocultures. Different varieties of the same crop are becoming increasingly similar in genetic composition. Once genetic differences are lost resistance against insects is less. Therefore, an insect plague or disease can successfully attack the respective crop and do damage to all varieties. The creation of a monocultures magnifies the effect of such an attack (Altieri, 1998). It should be noted here that crop production with monocultures, particularly in developing countries, runs the risk of being more susceptible to erosion as well as to price fluctuations due to economic business cycles. Moreover, some authors have claimed that malnutrition can be directly attributed to technology, as this has reduced the diversity of many diets and made people dependent on a small group of products (Grain, 2000). Modern biotechnology may contribute to an increase in the likelihood or magnitude of such effects of monocultures.

\section{Health issues}

One of the problems concerning genetic modification is that the inserted genes may cause allergic reactions in certain people. For example, the introduction of a gene of a Brazilian nut in soya beans caused allergic reactions from people allergic to the nut (McHugen, 2000). Scientists have countered this argument by mentioning that there has been only one known case in which it was a problem, and that in the future it will be possible to extract the gene causing the allergy (Royal Society, 1998). This, however, does not solve the current problem that genetic modification could cause future allergies. Without proper labeling this problem will remain and consumers could have an allergic reaction without being able to locate the possible source of the reaction.

One of the fears of new transgenic crops is that the insertion of a new gene may lead to an unexpected reaction and the production of toxins. The advantage of a GMO, however, is that the knowledge which genes have been inserted makes toxicological 
testing easier than in the case of an organism obtained through traditional crossbreeding (The Third World Academy of Sciences, 2000).

Another problem that has been pointed out is the insertion of antibiotics in crops. The antibiotics do not serve a purpose in the final product but have been inserted only to facilitate growth of the crop. When the final product is eaten, the antibiotic genes may come into contact with bacteria in the digestive system of people and animals, thus creating resistance against the respective antibiotics in these bacteria. This in turn could weaken future use of the respective antibiotic as a medicine. To counter this argument, researchers claim they have been successful in extracting antibiotics in certain cases before the respective food was developed for consumption (The Third World Academy of Sciences, 2000). Additionally, the risk and effects of the insertion of antibiotics is seen as relatively small compared with the current (ab)use of antibiotics as a prescription medicine for various diseases (The Royal Society, 1998).

\section{Population growth}

Do GMOs contribute to a stable food provision at a global scale, particularly in developing countries? It is often argued that the main problem is not so much the total supply of food, but its accessibility, distribution and sustainable production. In addition, socio-economic factors such as poverty play a role. Currently the food supply is sufficient for the entire world population, and hunger problems exist mainly due to a lack of income. Nevertheless, whether this is also the case in two or three decades remains to be seen. Scientists do not agree on how many people the Earth can feed on a sustainable basis. Wide variances in estimates (in the range of at least 1 to 50 billion people) are due to differences between studies in terms of assumptions regarding land use, daily required intake of energy, and type of diet (see the survey by Cohen, 1995). Many regard it as impossible to calculate the number of people that the earth can support, because it depends on so many complex interactions between natural, economic, technological and demographic factors. It certainly is not a matter of simple extrapolation.

One can therefore argue that population growth might be stimulated by increasing the capacity for food production through the application of modern agricultural biotechnology. There is some support for the view that the world is already overpopulated, notably because human pressure on ecosystems is beyond natural carrying capacities (Vitousek et al., 1986). Taking away barriers to further growth, such as limits to food production, risks further overshooting with ultimately ecological collapse in hindsight. Of course, in view of the above-presented estimation of world population figures this can be debated.

Although the food problem is often used to motivate further research on and application of agricultural biotechnology, most of the research up till now has gone into the development of commercial crops that benefit "western" producers (Altieri and Rosset, 1999).

\section{Social-economic issues}

Various environmental organizations have stated that the benefits of biotechnology are mainly economic ones, notably profits of large multinational companies. Is this statement supported by the facts? Genetic codes and biotechnological procedures are subject to patenting, which, in combination with product prices that insufficiently reflect 
environmental damages ("externalities" in economics' jargon), suggests that biotechnology applications are largely influenced by commercial interests (profit motives) rather than by balanced social evaluations.

Moreover, it is expected that a small number of very large firms will soon control the biotechnology market. Traditional seed companies have been and will continue to be bought by larger chemical and biotechnology ("life science") multinationals. These companies control a strategic package of products such as insecticides and herbicide resistant plants that allow for market and price control and cause barriers to entry for new firms. Farmers therefore become increasingly dependent on a very small number of firms supplying the needed seeds, fertilizers, herbicides, etc. (Krimsky and Wrubel, 1996). Due to the patent legislation they have to pay repeatedly (yearly) for seeds. In other words, they are legally not allowed to select seeds themselves, although this would give rise to a better adaptation of crops to local climate and soil conditions. As a consequence, farmers in developing countries will become more dependent on imported seeds, since most biotechnological companies are mainly based in the USA and Europe.

\section{Uncertainty, irreversibility, tradeoffs, and alternative options Risk perception}

Most of the issues raised by the pressure groups concerning health and environmental issues involve trying to influence the public safety feeling, in other words, influencing the level of a publicly acceptable risk. As Miller (1998) describes, in the public's perception unfamiliar risks tends to be overestimated. People generally have very little knowledge and understanding of the history of traditional biotechnology and the achievements of its application, let alone the application of modern biotechnology and genetic engineering. In this case little information at the right time can shift the balance of opinions. This is undesirable, since often the information is partial or simply incorrect. An example of the difference in perception of risk between the public and the scientific community is the issue of health concerns. While the public sentiment against genetically modified crops remains negative mainly due to worries about health problems, a recent press statement by the National Research Council sums up the scientific risk: "... the committee is not aware of any evidence suggesting that foods on the market today are unsafe to eat as a result of genetic modification. Furthermore, we found no strict distinction between the health and environment risk posed by plants modified through modern genetic engineering techniques and those modified by conventional breeding practices." (Adkinson, News Conference 2000, paragraph 11,12). Nuffield Council on Bioethics (1999) makes similar statements.

\section{Endogenous risk}

One cannot assume that risks relating to GMO's are absolute or exogenous (Crocker and Shogren, 1999). For instance, in the present context a risk affecting strategy is to limit hybridization (Hails, 2000). This can be done, among others, with terminator technology, which allows the genetic control of sterility by preventing pollen development or seed germination. Such strategies may impact both the likelihood that something will happen and the impact of the outcome. Notably the health related effects, and their probabilities, of biotechnology can be adapted by ex ante and ex post actions. Ex ante, human responses to new products can be tested. Ex post, consumers can decide not to buy 
certain products, farmers to move away from certain areas, etc. Protection can also result from public intervention. All in all, this means that risks of using biotechnology should not be considered as objective and exogenous. Risk can be changed by management and endogenous responses to perceived or real risks. Moreover, some types of risks are insurable. Consequently, risk management in this area should take both natural and social-economic aspects into account, in order not to be (at best) inaccurate or (at worst) ineffective.

The most serious risks, however, relate to ecological damages. Insurance against these is often impossible. The impact, such as evolutionary change or loss of ecosystem functions, is irreversible and cannot be compensated in financial terms. This brings us to the next consideration.

\section{Irreversibility of lost opportunities}

The problem of choosing for or against genetic modification of agricultural crops can be cast in a framework of opportunities and irreversible or even path-dependent development. These are themes that have been studied in evolutionary economics and economics of technology (Arthur, 1989) and economics of nature conservation (Fisher and Krutilla, 1985; Porter, 1982). The results of these studies indicate that the historical development of technology may be far from economically or socially optimal, since technologies get locked in due to increasing returns and network externalities. This has relevance for a number of problems studied nowadays, including climate change (Kolstadt, 1994) and biotechnology. Different biotechnology scenarios are associated with lost opportunities due to certain irreversible processes. Two extreme case scenarios are particularly relevant in this context.

In a first scenario with large investments made in biotechnology, the irreversibility of the resulting quick progress in biotechnology applications has both economic and ecological-evolutionary elements. Economic irreversibility is due to an increased dependence of agriculture on GMOs. Ecological-evolutionary irreversibility involves changes in the genetic composition of species, both crops, wild relatives and ecologically related species.

Another scenario is the rejection of genetically modified products by western consumers, which to some extent, is currently happening in most countries in Europe. This can eventually have a large negative impact on the biotech industry. This would result in potentially foregone future benefits for people now and in the future. Presently, the conditions set by donors of development aid and by financial institutions on the use of biotechnology already force many developing countries to restrain the import of both genetically modified crops and its technology (Paarlberg, 2000). The result is that while the discussion of genetically modified crops goes on in the west, the developing nations are unable to make their own choices.

\section{Benefit-cost tradeoffs and comparison with alternatives}

Is it reasonable to compare benefits and costs, possibly with correcting for risk-factors? Can this serve as a tool for evaluating biotechnology scenarios? In other words, are the uncertain benefits worth the uncertain costs? The analysis is complicated, partly since the uncertainty is magnified by endogenous ex ante and ex post modification of risks for both ecosystems and human health. For instance, some people clearly put a much larger 
weight on the potential benefits of biotechnology for developing countries, notably supporting a food supply for a growing world population, than on the various costs associated with biotechnology.

Various authors state that a fair comparison of biotechnology scenarios with alternative options should not come down to a comparison between GMO based products and a lack of these, but between GMO based products and conventional agricultural technology (Hails, 2000; The Third World Academy of Sciences, 2000; Tramper, 2000).

The latter is characterized by intensive production, irrigation, and notably use of pesticides, herbicides and fungicides. It is evident that a shift to biotechnology is an improvement in many respects, and will not perform structurally worse in others. For example, external use of insecticides will have a similar - in magnitude that is evolutionary (or selection) effect as plants with genes producing the same insecticide (Krimsky and Wrubel, 1996). Another example is that traditional agriculture also has caused gene flows from crops to wild varieties. Hails (2000) gives the example of weed beet being a hybrid between sugar beet and wild beet.

Should traditional agriculture, with all its disadvantages for health and environment, act as a benchmark when judging modern biotechnology? This depends on the availability of a third alternative, which might be organic farming. The question is whether the latter is capable of providing sufficient food to support the world population, and how quickly it can be developed compared with alternative scenarios based on GMOs. Only if organic farming is a real alternative can it serve as the benchmark.

\section{Evaluation and recommendations}

The currently available genetic technology in agriculture mainly focuses on two applications, namely herbicide tolerant and insecticide producing crops. This has in some cases improved the conditions for western farmers while the only effect it has had on consumers is to raise doubts about its safety. The information on both the positive and negative effects of genetically modified crops on human health and the environment indicates that the effects up till now are minimal. Most scientists involved in the use and application of biotechnology perceive long-term benefits and are largely in favor of its use. They view the environmental and especially health risks involved as minimal and acceptable and regard the potential benefits to outweigh the potential risk. However, low risk does not mean no risk, and if the negative effects are larger than expected the potential damage could be great and irreversible. What are the considerations that need to be taken into account to arrive at a balanced judgement of the use of GMOs in agricultural crops?

The most fundamental characteristics of modern biotechnology from a natural science perspective is that changes due to genetic engineering are no longer subject to natural selection, and that species boundaries are no longer absolute. With regard to the latter, the most extreme example is the mixing of animal and plant genes in single chromosomes. The first feature, not being subject to natural selection, applies also to classical crossbreeding, but the second one is entirely new. Traditional crossbreeding usually implies a trade-off or compromise between one characteristic (e.g., productivity or color) and another characteristics, resulting in organisms that are usually very sensitive outside a controlled domesticated context, making their spread in nature unlikely. Genetic 
engineering, however, can circumvent compromises, leading to a relatively high risk of spreading the resulting organisms in natural environments.

The gene flow is not the only possible environmental impact. Biodiversity loss is a general category of impacts, which covers damages to crops, wild relatives, pesticides, and the wider ecosystem. For instance, herbicide resistant organisms stimulate the use of herbicides, antibiotic resistant species create health risks, and genetic engineering in general stimulates monocultures that in turn promote erosion and quickly spreading diseases. Unfortunately, field experiments with genetically modified crops in isolated areas do not provide sufficient information about ultimate ecosystem impacts of using such crops in normal agricultural circumstances. This suggests that applications of GMOs are always experiments and need to be monitored closely.

Next, health effects of biotechnology are often exaggerated. Allergies due to GMOs can be foreseen or tested and only a few problems have appeared so far. Nevertheless, research on environmental and health effects is relatively small compared with research on commercial application of genetically modified crops. One should strive for more balance in this respect.

The advantages of genetically modified organisms are overstated. Creating features like resistance against desiccation and viruses are much more difficult to arrange because they are the result of interplay of many particular genes. Moreover, the main reason for the marketing of the current GMOs is not solving the world's food problem, if there is such a problem, but straightforward commercial, profit oriented interests. Finally, proponents of genetically modified organisms exaggerate the precision, focus and capabilities of the technique. So, although the development of GMOs is relatively new and the technology is starting to develop, these considerations suggest that optimism about the beneficial effects of GMOs needs to be tempered.

The public, which has not yet reaped any direct benefits from genetically modified crops, continues to have a blurred vision of what the involved potential benefits and risk are. The effect of this is felt not only in western countries where acceptance of genetically modified crops is minimal, especially in Europe, but also in developing countries where the adoption of biotechnology has been insignificant. Since the potential value of biotechnology is perhaps greatest in developing countries, it seems obvious that they increase their influence on debates and policies relating to biotechnology. Though biotechnology is neither the only answer nor a complete answer to the world's food problems, it could play a significant role in improving both the quantity and quality of food that is produced worldwide. But if biotechnology is to serve this role for humanity then its R\&D and application need to be better monitored and steered by social evaluations and better informed politicians and voters, rather than only by interests of profit seeking multinationals and their shareholders.

In view of the many uncertainties and different perceptions of these, as well as the problem of trading-off advantages or benefits against disadvantages or costs, a simple evaluation of different biotechnology scenarios is very difficult. This partly explains the wide range of opinions among organizations and experts. Nevertheless, a careful judgement is that the long-term benefits related to production, health and environment are clearer and more certain than the disadvantages in terms of health and ecological effects. Moreover, when comparing agricultural biotechnology with traditional agricultural practices based on pesticide use, which brings along many environmental and health 
related risks, it is evident that a shift to biotechnology is an improvement in many respects. The question, however, is whether traditional agriculture should be the benchmark in evaluations of modern biotechnology. Many writers on biotechnology assume or explicitly state so. At first sight, the long term impact of modern biotechnology may seem much more severe than that of traditional agriculture. But the evolutionary consequences of modern biotechnology are not new compared with traditional agriculture, so that it is debatable whether they create an extra dimension to the uncertainty about (very) long run impacts. A more systematic comparison, including also organic agriculture, could support a better judgement of agricultural biotechnology. This requires, however, that organic farming is described as a real alternative with the full significance of all derived implications.

Modern biotechnology is subject to much R\&D. Many genetically modified products are already sold on the market. Agricultural biotechnology is especially rapidly diffusing in countries like Argentina, China and the USA. This suggests that the most realistic public strategy would be to quickly develop national and international legislation that focuses on responsibilities, norms and methods for ex ante testing and ex post monitoring of environmental, ecological and health-safety aspects of such products. At the same time, democratic decisions need continuous support from scientists that explain in clear ways the pros and cons of biotechnology in understandable and non-emotional terms.

Different views exist with regard to the design of public policies aimed at influencing $R \& D$ and investments in biotechnology. From an uncertainty perspective a comparison with nuclear energy seems relevant, which would suggest a policy based on the precautionary principle, i.e. producers of GMOs need to prove that negative effects are insignificant. Another view is that it is impossible to avoid all risks, which is neither chosen as a constraint in other areas of public policy - think of accidents in transport. A third view is that people have influenced nature significantly since the beginning of agriculture, i.e. the early domestication of animals and plant species. This has led to the development of culture and trade, and has stimulated population growth (see Diamond 1997). From this perspective the emotional argument "GMO food is unnatural" is irrelevant; humans inevitably influence and control nature, and are completely dependent on non-natural food, be it produced with or without genetic engineering technology. Finally, it has been argued that consumers need to decide themselves, implying that choice freedom is essential, especially since a discussion based on purely scientific pros and cons will never lead to a simple conclusion. It is difficult to guarantee food choice freedom, notably the choice of GMO-free products, when GMOs are used at a large scale. Ecolabelling, more control and reporting, and separation of product flows are some of the actions needed preserve this freedom. Nevertheless, the latter assumes that it is possible to completely separate material-product cycles without GMOs from those with GMOs. Even if this were possible it would be very costly; so-called "Identity Preservation Systems" are needed. Moreover, such a "free choice approach" denies the public goods (bads) character of impacts of GMOs on health and ecosystems (biodiversity). For this implies that people cannot protect themselves against all undesirable effects, notably ecological changes. In other words, completely free choice is impossible. Moreover, international relations and trade threaten the freedom of choice. The USA, for instance, has argued that other partners, notably the EU, are creating trade 
barriers by not allowing products based on GMOs. All in all, policy design aimed at free choice by consumers is not a simple matter. ${ }^{2}$

\section{Acknowledgements}

We are grateful to Martijn van der Heide, Rutger Hoekstra, Paulo Nunes and Cees Withagen for helpful comments. Of course, we take full responsibility for any remaining errors and omissions, as well as for all opinions expressed.

\section{References}

Adkinson, P. News Conference, 2000. Genetically Modified Pest-Protected Plants: Science and Regulation, National Research Council, April 5, 2000.

Altieri, M.A. 1998. The environmental risks of transgenic crops: an agroecological assessment. In: Proceedings of an Associated Event of the 5th Annual World Bank Conference on Environmentally and Socially Sustainable Development. I. Serageldin and J.Martin Brown (eds), Washington, DC, October 1998.

Altieri, M. and P. Rosset, 1999. Ten reasons why Biotechnology will not ensure food security, protect the environment and reduce poverty in the developing World, Agbioforum 2(3\&4), Summer/Fall 1999

Arthur, B., 1989. Competing technologies, increasing returns, and lock-in by historical events. Economic Journal 99(394), March, 1989, pp. 116-131.

Committee on Agriculture, FAO, 1999. Biotechnology, Fifteenth Session, Rome, 25-29 January, 1999.

Cohen, J.E., 1995. How Many People can the Earth Support? Norton, New York.

Conway, G., 2000. Food for all in the 21st Century, Environment 42(1), Jan/Feb, 2000, pp. 9-18

Crocker, T.D., and J.F. Shogren, 1999. Endogenous environmental risk. In: J.C.J.M. van den Bergh (ed.). Handbook of Environmental and Resource Economics. Edward Elgar, Cheltenham.

Diamond, J., 1997. Guns, Germs and Steel: A Short History of Everybody for the Last 13000 Years. W.W. Norton, New York.

Fisher, A., and J. Krutilla, 1985. Economics of nature preservation. In: A.V. Kneese and J.L. Sweeney (eds.). Handbook of Natural Resource and Energy Economics. NorthHolland/Elsevier, Amsterdam.

Grain, 2000. Engineering Solutions to Malnutrition. Seedling 17(1), March 2000.

Greenpeace online, http://www.greenpeace.org/ geneng/.

Hails, R.S., 2000. Genetically modified plants - the debate continues. Trends in Ecology and Evolution 15(1), pp. 14-18.

James, C. 1999. Preview Global Review of Commercialized Transgentic Crops: 1999. ISAAA Briefs, Makati City.

Klotz-Ingram, C., S. Jans, J. Fernandez-Cornejo, W. McBride, 1999. Farm-level production effects related to the adoption of genetically modified cotton for pest management. Agbioforum 2(2), Spring, 1999.

\footnotetext{
${ }^{2}$ Further policy suggestions cover areas like health and safety control, public funding of research, intellectual property right regimes, and international policy coordination and agreements relating to biotechnology. The Third World Academy of Sciences (2000) provides many useful suggestion on these.
} 
Kohlstadt, C.D., 1994. The timing of CO2 control in the face of uncertainty and learning. In: E.C. van Ierland (ed.). International Environmental Economics. Elsevier, Amsterdam.

Krimsky, S. and R. Wrubel, 1996. Agricultural Biotechnology ad the Environment. Science, Policy and Social Issues, University of Illinois Press, Urbana and Chicago

Leislinger, K.M., 1999, The ethical challenges of green biotechnology for developing countries. The International Conference on Biotechnology CGIAR - National Academy of Sciences. The World Bank, Washington D.C., October 21-22, 1999.

Le Buanec, B. 1999. Transgenic plants and food security. Industry and Environment 22(2-3), April-September, pp. 51-54.

Losey, J., L Rayor, M. Carter, 1999. Transgenic pollen harms monarch larvae, Nature 399(214), May 20, pp. 214.

MacKenzie, D., 1999. Unpalatable truths. New Scientist 162(2182), 17 April, pp. 18-19.

Mazur, B., E. Krebbers, S. Tingey, 1999. Gene discovery and product development for grain quality traits. Science 285(5426), July 16, pp. 372-375.

McGloughlin, M., 1999. Ten reasons why biotechnology will be important to the developing world. Agbioforum 2(3-4), Summer/Fall, 1999.

McHugen, A. 2000. Biotechnology and Food, second edition. American Council on Science and Health, New York, September 2000.

Miller, H., 1998. The emotional response to risk: inevitable but not unmanageable. Agbioforum 1(1), summer, 1998.

Morrison, S. and G Giovanetti, et al. 1998. Biotech 99: Bridging the Gap; Ernst \& Young's $13^{\text {th }}$ Biotechnology Industry Annual Report. Ernst \& Young LLP, Palo Alto, December 1998.

Nuffield Council on Bioethics, 1999. Genetically Modified Crops: Ethical and Social Issues. London, May, 1999.

Paarlberg, R., 1999. Agrobiotechnology choices in developing countries, Center for International Development.

Paarlberg, R., 2000. Genetically modified crops in developing countries: promise or peril? Environment 42(1), Jan/Feb, 2000, pp. 19-27.

Peng, J.R., et al., 1999. "Green Revolution" genes encode mutant gibberellin response modulators. Nature 400(6741), July 15, pp. 256-261.

Porter, R.C. 1982. The New Approach to Wilderness Preservation through Benefit-Cost Analysis. Journal of Environmental Economics and Management, 9(1), pp. 59-80.

The Royal Society, 1998. Genetically Modified Plants for Food Use. Royal Society Report, London. September, 1998.

Reijnders, L., 2000. Valse start/misgekleund: eerste golf biotechgewassen in diskrediet. Natuur en Milieu 24(7), September, pp. 26-29.

Shah, M. and M. Strong, 1999. Food in the $21^{\text {st }}$ Century: from Science to Sustainable Agriculture. World Bank, October 1999. Washington D.C.

Stix, G., 1998. Resistance Fighting, Will Natural Selection outwit the King of Biopesticide?. Scientific American, 278(5) May 1998, pp. 21-22.

Tramper, H., 2000. Nederland als transgeen productieland. Natuur \& Techniek Wetenschapsmagazine, 68 jaargang, Juli/August 2000, pp. 91-94.

Union of Concerned Scientists, http://www.ucsusa.org/ 
Vitousek, P.M., P.R. Ehrlich, A.H. Ehrlich, and P.A. Matson, 1986. Human appropriation of the products of photosynthesis. Bioscience 34, pp. 368-373.

The Third World Academy of Sciences, 2000. Transgenic Plants and World Agriculture. The Royal Society, London. 